\title{
Applying the ARIMA Model to the Process of Forecasting GDP and CPI in the Jordanian Economy
}

\author{
Abdullah Ghazo ${ }^{1}$ \\ ${ }^{1}$ Department of Economics of Financial and Business, Faculty of Economics and Administrative Sciences, Al- \\ Albayt University, Mafraq, Jordan \\ Correspondence: Abdallah Ghazo, Department of Economics of Financial and Business, Faculty of Economics and \\ Administrative Sciences, Al- Albayt University, P.O.BOX 130040- 25113, Mafraq, Jordan. E-mail: \\ aghazo@aabu.edu.jo \\ Received: October 26, 2020 \\ Accepted: December 18, $2020 \quad$ Online Published: January 11, 2021 \\ doi:10.5430/ijfr.v12n3p70 \\ URL: https://doi.org/10.5430/ijfr.v12n3p70
}

\begin{abstract}
Gross Domestic Product (GDP) and consumer price index (CPI) are significant indicators to describe and evaluate economic activity and levels of development. They are also often used by decision makers so as to plan economic policy. This paper aims at modeling and predicting GDP and CPI in Jordan. In order to achieve this goal, the study applied the Box- Jenkins (JB) methodology for the period 1976-2019. Based on the results, ARIMA $(3,1,1)$ found to be the best model for the GDP. In addition, ARIMA $(1,1,0)$ was the best model for forecasting the CPI. The results were supported with the findings of the stationarity and identification rules test of time series under using AIC and SIC criterion. The forecasted values of the GDP and the CPI for the next three years (2020-2022) were (29342.12, 32095.10 , 35106.36 million JD) and $(128.31,133.28$, 139.28) respectively. Compared with 2019, the GDP is forecasted to decrease in 2020, while the CPI is forecasted to increase in 2020. This implies that the Jordanian economy is tending toward stagflation. After 2020, both GDP and CPI increased, which indicates that Jordanian economy is tending toward cost-push inflation.
\end{abstract}

Keywords: gross domestic product, consumer price index, forecasting, ARIMA

\section{Introduction}

Accurate forecasting of gross domestic product (GDP) and consumer price index (CPI) is a convenient way to get an idea of the general direction of economic activity in the future needed to frame proper economic development strategies, economic policies, and to allocate funds according to diverse priorities of the government. Parkin (2011) defined GDP as the market value of all final goods and services produced within the borders of a nation in a given time period often (annually, semiannually, and quarterly). GDP is also considered as an important indicator for assessing the national economic development and judging the employment status of the economy as a whole. Therefore, forecasting its values is an interesting topic for researchers and policy makers in the field of business in general and economics in particular to set up economic developmental strategies and policies (Dongdong, 2010). The importance of the GDP grows when economy is expected to go through extraordinary circumstances such as the recent Corona virus pandemic that is currently sweeping the entire world, and certainly would affect the GDP.

The primary focus of monetary and fiscal policies has been to maintain low and stable levels of the CPI which used to calculate inflation rate and to assess the effectiveness of the economic policies adopted by the government. Continuous rise in inflation rates leads to distortions in economy through reducing the purchasing power of the national currency as well as affecting economic growth rates because investment projects become riskier. Likewise, consumption, saving and real wages are affected by inflation; it even causes inequality in distributing income (Kharimah, et al., 2015). Therefore, it is necessary to predict the future levels of prices. These predictions can guide central banks and economic decision-makers to make the best monetary and fiscal policies that match those expectations and avoid inaccurate decisions that might have negative effects on investment, consumption, saving and other macroeconomic variables and then on economic stability (Nyoni, 2019).

\section{Literature Review}

Previous studies used diverse approaches to forecast economic time series. One of the approaches is known as 
univariate forecasting or Autoregressive Integrated Moving Average (ARIMA) model developed by Box and Jenkins (1976). In this model, a time series is expressed in terms of the past values of itself (the autoregressive component), in addition, to current and lagged values of a white noise error term (the moving average component). This approach has been extensively used by many researchers in forecasting studies. The popularity of this approach stems from the fact that this approach has proven its ability to accurately predict if all the conditions of its application are fulfilled. Among these studies is the study of Kenny and al. (1998) which used ARIMA model to forecast the Irish inflation after outlining the practical steps that were needed to determine the integrated degree, the number of autoregressive terms, and the number of the moving average terms in the time series used in models to forecast the Irish inflation. The result found that the forecasted values of the consumer price index are harmonized with real values.

The study of Dongdong (2010) used monthly CPI data from January 2000 to December 2009. After statistically identifying the correlation function and the partial correlation function of CPI, stationary test, and ARIMA model residual serial autocorrelation, empirical results showed that $\operatorname{ARIMA}(12,1,12)$ model provided a better prediction of the monthly CPI in China after 2010 in the hope that the government will formulate an appropriate monetary policy for that. Kiriakidis and Kargas (2013) used ARIMA model to forecast the Greek GDP. The forecasted results successfully anticipated the recession that took place in the Greek economy later on. Kharimah et al. (2015) investigated the process of forecasting the consumer price index of Bandar Lampung. After evaluating the stationarity of the data, the correlogram of ACF and the correlogram of PACF, it was found that the best model for achieving their target was ARIMA $(1,1,0)$. It helped them to forecast that Bandar Lampung's CPI will be on the rise in the future. Dritsaki (2015) used one ARIMA $(1,1,1)$ model over the period 1980-2013 to forecast the real GDP in Greece during for the period 2015 to 2017. Statistical results showed that Greece's real GDP is steadily improving.

Furthermore, Yang, et al. (2016, December) applied ARIMA $(2,2,2)$ model to predict the gross domestic product in China. Results showed that this model is effective in forecasting GDP only in a short term. Wabomba et al. (2016) used the data obtained from the Kenya National Bureau of statistics for the years 1960 to 2012 to model and forecast the Kenyan GDP applying ARIMA models. The results of an in-sample forecast showed that the relative and predicted values were within the range of $5 \%$ of actual values, so the forecasting power of this model was relatively adequate and efficient in modeling the annual returns of the Kenyan GDP in future. Uwimana et al. (2018) applied ARIMA model to 20 of Africa's largest economies in order to forecast future time series values. Based on the estimation results, the paper concluded that from 1990 looking forward to 2030, there will be an increasing GDP growth, whereas the average speed of the economy of Africa will be of 5.52\%. Agrawal (2018) attempted to model and forecast real GDP in India by applying ARIMA and using publicly available quarterly real GDP data from 1996, Quarter 2 to 2017 Quarter 2. The results shows that all the forecast seem to be converging in the long run. Abonazel and Abd-Elftah (2019) found that the appropriate statistical model for forecasting the Egyptian GDP is ARIMA (1, 2, 1), this model was used forecast the GDP of Egypt until 2026. According to the forecasted values GDP is expected to continue rising. After reviewing some examples of previous studies that have succeeded in reaching estimates that were close to the actual values of the estimated economic variables by the ARIMA methodology, this study use the same methodology after modifying it by adding the error variance to ARIMA regression model, to make the model more forecasting fit.

\section{Methodology and Results}

The new generation of forecasting tools that are used to predict and control future values of phenomena, popularly known as the Box-Jenkins (BJ) methodology, and technically known as the ARIMA methodology, have proven themselves to be relatively robust, especially when generating short time series forecasts. In general, ARIMA models frequently outperform more sophisticated structural models in terms of short forecasting ability. However, this paper focuses on ARIMA models which constitute an alternative forecasting approach for multivariate time series forecasting. It also includes only the time series being forecast and requires a stationary time series to get an estimated model that can be used for forecasting. It is worth noting that this model has valid and reliable features through time, particularly over future time periods (Kenny and Quinn, 1998). To establish a best suitable ARIMA $(\mathrm{p}, \mathrm{d}, \mathrm{q})$ model for forecasting GDP and CPI, where $p$ denotes the order of autoregressive terms $(A R(p))$ as:-

$\left(Y_{t}-\mu\right)=\beta_{1}\left(Y_{t-1}-\mu\right)+\beta_{2}\left(Y_{t-2}-\mu\right)+\ldots .+\beta_{p}\left(Y_{t-p}-\mu\right)+v_{t}, \mu$ is the mean of $\mathrm{Y}, v_{t}$ is white noise

stochastic error terms, $d$ is the number of times the series which has to be differenced before it becomes stationary, and $q$ is the order of moving average terms $(M R(q))$ as: 
$Y_{t}=\delta+\alpha_{0} v_{t}+\alpha_{1} v_{t-1}+\alpha_{2} v_{t-2}+\ldots .+v_{q} v_{t-q}, \delta$ is constant, $v_{t}$ as mentioned before. We started with a stationary test to assess whether the data collected are stationary or not by depicting a graph of time series for both (GDP) and (CPI) which is shown in Figure 1.

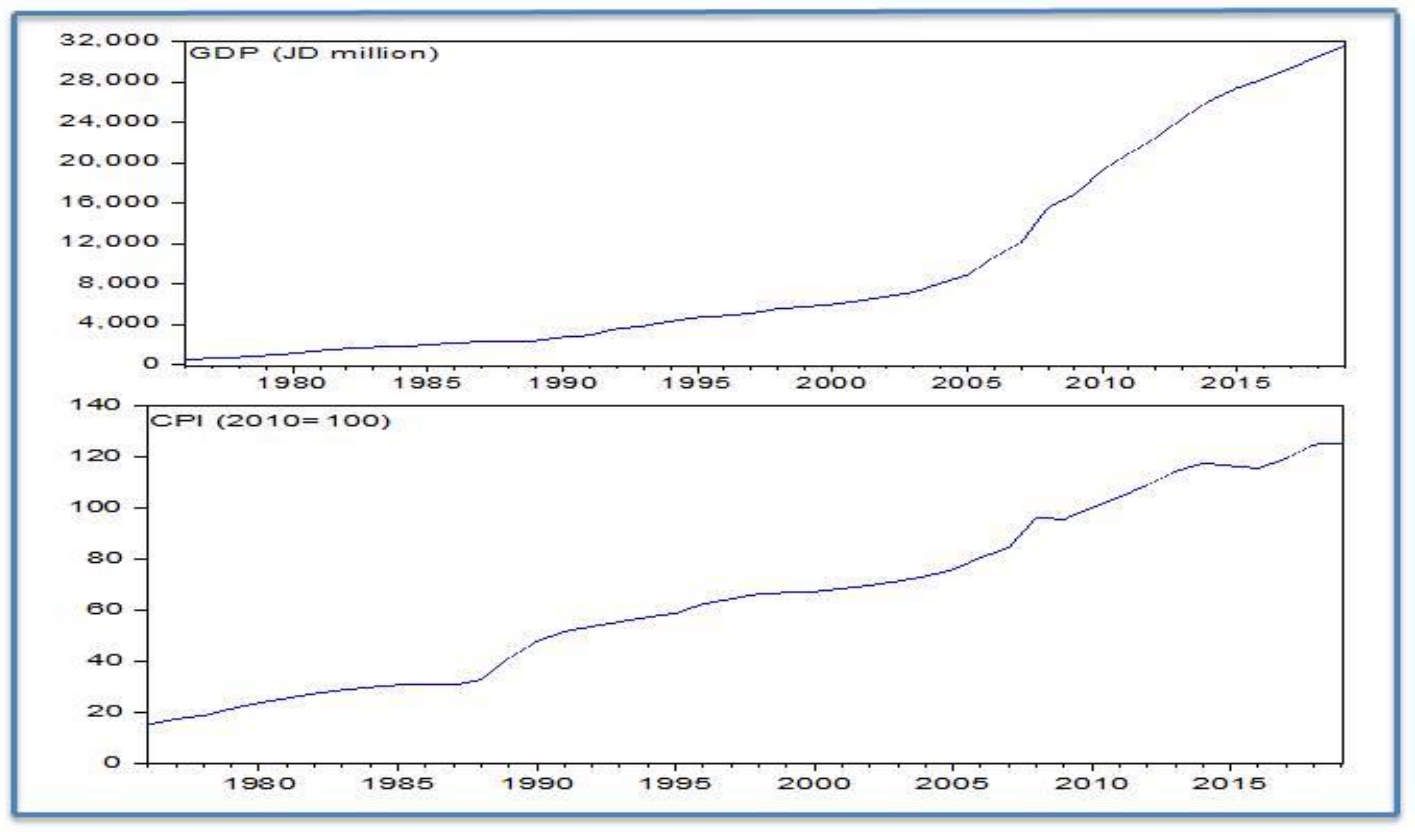

Figure 1. GDP and CPI data during $1976-2019$

As shown in the figure above, both variables are approximately follow exponential form with a general increasing trend. In other words the original GDP and CPI sequence are non-stationary. However, In order to confirm this conclusion, we plotted the Autocorrelation Function (ACF) and the Partial Autocorrelation Function (PACF) against lags which are known as (Correlogram) to both series, as shown in Figure 2 below.

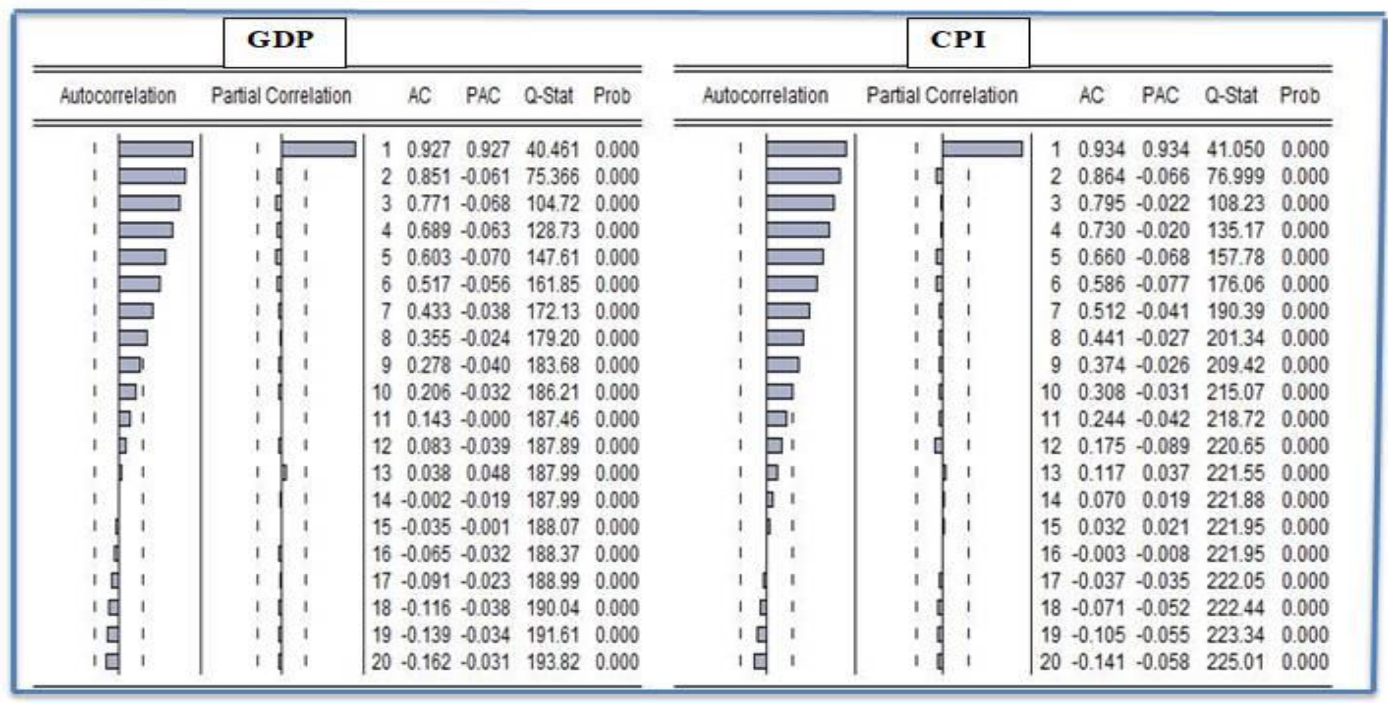

Figure 2. Correlogram of GDP and CPI (Level) 
The figure clearly shows that the most striking feature of this correlogram is that the autocorrelation coefficients at various lags are high even up to a lag of 9 for GDP, and up to a lag 10 for CPI. In addition, the Q-statistic of Ljung-Box (1978) at the 20th lag has a probability value of 0.000, so we can conclude that GDP and CPI series are non-stationary. Thus, the series must be transformed to be stationary (Mills, 1990) and (Gujarati \& Porter, 2009). To eliminate non-stationarity, we took the natural logarithm of GDP and CPI, thus obtaining two new variables named LGDP and LCPI respectively. After applying the Augmented Dickey-Fuller (ADF) test and Phillips-Perron (PP) test to both series, the results showed that LGDP and LCPI series were still non-stationary. Therefore, the first-order difference was taken, for both series producing two new variables DLGDP and DLCPI. These variables proved to be stationary as confirmed by the results of the ADF test and PP test shown in Table 1.

Table 1. Unit Root Tests

\begin{tabular}{|c|c|c|c|c|c|c|c|}
\hline \multirow[t]{2}{*}{ Test } & \multirow{2}{*}{\multicolumn{2}{|c|}{ variable }} & \multicolumn{3}{|c|}{ Test critical values } & \multirow{2}{*}{$\begin{array}{c}\text { Augmented } \\
\text { Dickey-Fuller test } \\
\text { statistic }\end{array}$} & \multirow[t]{2}{*}{ decision } \\
\hline & & & $1 \% \quad$ level & $5 \%$ level & $10 \%$ Level & & \\
\hline \multirow{6}{*}{ ADF } & \multirow{3}{*}{ LGDP } & $\mathrm{C}$ & -3.60 & -2.94 & -2.61 & -0.37 & Non- stationary \\
\hline & & $\mathrm{C} \& \mathrm{~T}$ & -4.20 & -3.52 & -3.19 & -1.94 & Non- stationary \\
\hline & & $\mathrm{N}$ & -2.62 & -1.95 & -1.61 & -0.03 & Non- stationary \\
\hline & \multirow{3}{*}{ DLGDP } & $\mathrm{C}$ & -3.63 & -2.95 & -2.61 & -3.17 & stationary \\
\hline & & $\mathrm{C} \& \mathrm{~T}$ & -4.20 & -3.52 & -3.19 & -2.08 & Non- stationary \\
\hline & & $\mathrm{N}$ & -2.62 & -1.95 & -1.61 & -1.52 & Non- stationary \\
\hline \multirow{6}{*}{ PP } & \multirow{3}{*}{ LGDP } & $\mathrm{C}$ & -3.39 & -2.93 & -2.60 & -1.85 & Non- stationary \\
\hline & & $\mathrm{C} \& \mathrm{~T}$ & -4.19 & -3.52 & -3.19 & -2.82 & Non- stationary \\
\hline & & $\mathrm{N}$ & -2.62 & -1.95 & -1.61 & 5.46 & Non- stationary \\
\hline & \multirow{3}{*}{ DLGDP } & $\mathrm{C}$ & -3.59 & -2.93 & -2.60 & -3.99 & stationary \\
\hline & & $\mathrm{C} \& \mathrm{~T}$ & -4.19 & -3.52 & -3.19 & -4.37 & stationary \\
\hline & & $\mathrm{N}$ & -2.62 & -1.94 & -1.61 & -2.15 & stationary \\
\hline
\end{tabular}

C: intercept include in test equation. C\&T: intercept and trend include in test equation. N: no intercept and trend include in test equation.

After getting a stationary sequence, the next step is to identify the model, i. e., to determine the values of the parameters $\mathrm{p}$ and $\mathrm{q}$ in ARIMA ( $\mathrm{p}, \mathrm{d}, \mathrm{q})$ model. According to the correlogram of the stationary series (DLGDP) and (DLCPI), the lag at which the PACF cuts off is the indicated value of $p$, and the lag at which the ACF cuts off is the indicated value of $q$ (Anderson, 1976) and (Box et al, 2015). Moreover, $(\mathrm{d}=1)$ as the model is stationary at the first differences.

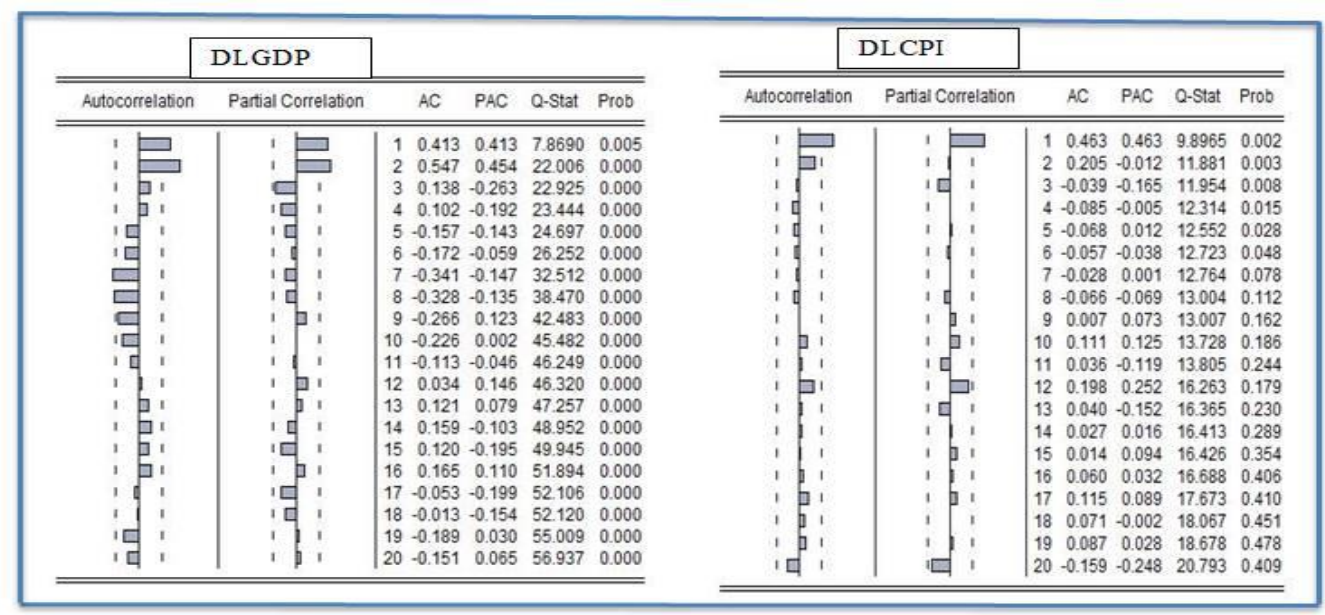

Figure 3. Correlogram of GDP and CPI (first difference of logarithm) 
Referring to Figure 3 above, we can conclude that the autocorrelation coefficient for the DLGDP series is significantly non-zero when the lag order is $(1,2,7,8,9)$, representing the values that $q$ can take. The partial autocorrelation coefficient for the DLGDP is significantly non-zero when the lag order is $(1,2,3)$, so $p=1,2,3$ and $\mathrm{q}=1,2,7,8,9$, and these values can be taken into consideration. In the same way, we can conclude that $\mathrm{P}=1$ and $\mathrm{q}=1$ for DLCPI. Based on the previous results, we have an alternative combination of $\mathrm{P} \& \mathrm{q}$ to be considered parameters of ARIMA model. In order to forecast GDP and CPI (Gujarati, and Porter, 2009) and based on E-views software, that combination can be made automatically, and an optimal one can be chosen based on minimum AIC and SIC and a maximum coefficient of the determinant. Results indicated that the ARIMA $(3,1,1)$ is a good fit model for forecasting GDP and ARIMA $(1,1,0)$ is a good fit to forecast CPI as shown in Figure 4 below.

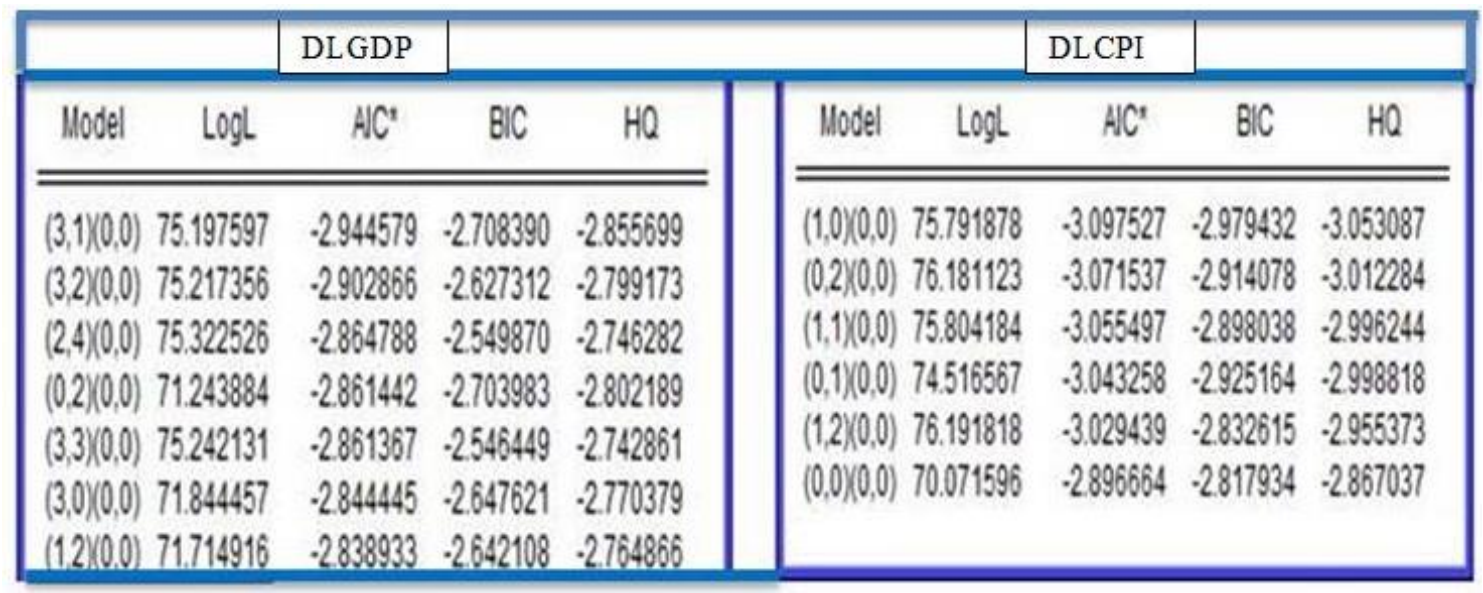

Figure 4. Model selection criteria table

One of the chosen fitted models which are summarized in Figure 4 is ARIMA $(3,1,1)$. It can be applied to DLGDP in order to forecast the values of GDP. The other one is ARIMA $(1,1,0)$ which can be applied on DLCPI to forecast the values of CPI during the next three years $(2020,2021,2022)$ respectively. They have been estimated with the results as (Note 1):

$$
\begin{aligned}
& D L G D P_{t}=0.089+1.075 D L G D P_{t-1}+0.368 D L G D P_{t-2}-0.646 D L G D P_{t-3}-v_{t-1}+0.001 S I S Q \\
& \mathrm{t} \text {-calculate }=(36.48) \quad(9.26) \quad(1.90) \quad(-5.42) \\
& \text { R-squared }=0.55 \\
& D L C P I_{t}=0.05+0.502 D L C P I_{t-1}+0.002 S I S Q \\
& \mathrm{t} \text {-calculate }=(4.04) \quad(3.66) \quad(4.64) \quad \text { R-squared }=0.38
\end{aligned}
$$

After estimating the models, diagnostic checking would be necessary to confirm that the estimated models are reasonably suitable and statistically significant for forecasting. One of simple diagnostic methods is to obtain the correlograms of ACF and PACF of the residuals models (1,2). The estimated ACF and PACF are shown in Figure 5 which illustrates that the correlograms of both ACF and PACF give the impression that the residuals estimated from models 1 and 2 are purely random (white noise). Therefore, there may not be any need for another ARIMA models to be used during the process of estimation. 


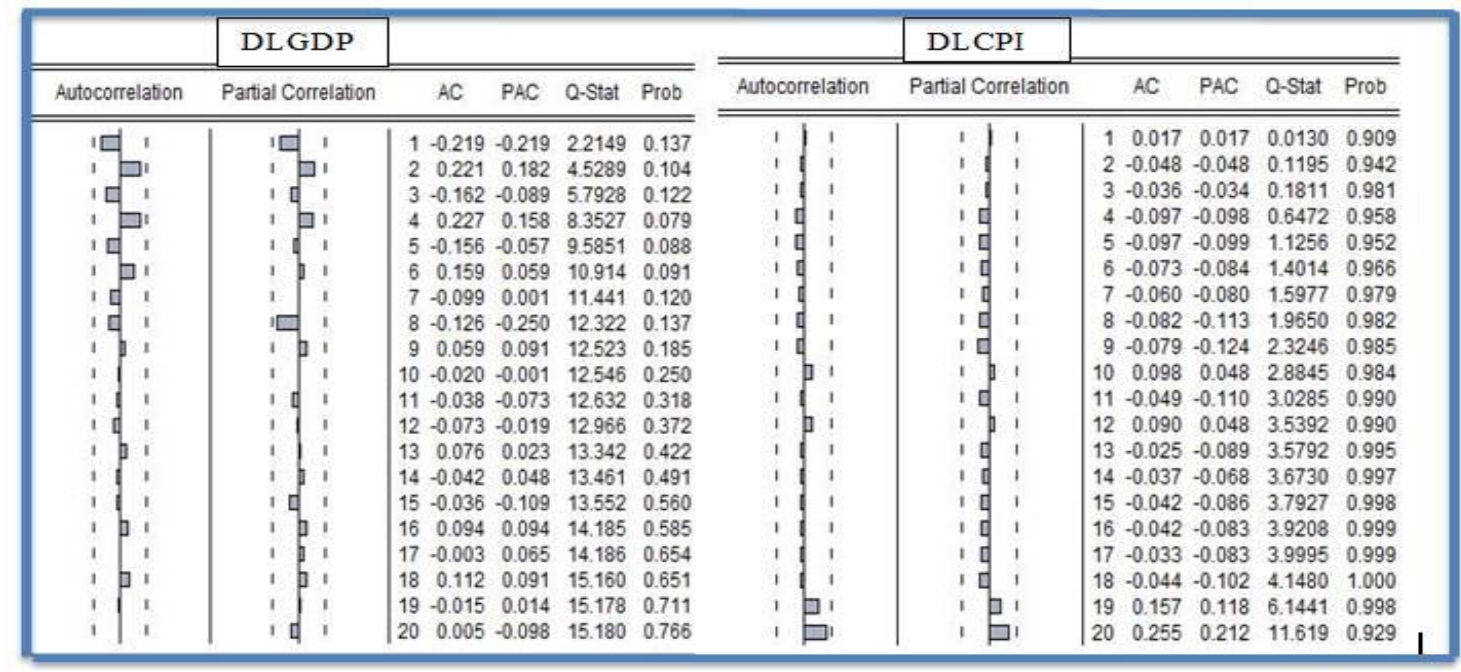

Figure 5. Correlogram residuals of Models $1 \& 2$

After the diagnostic checking had been completed successfully, we could forecast GDP using model (1). This can be done by removing the transformation of the first difference and taking the antilog to get the values of GDP on level. The same procedure could also be carried out for CPI. Table (2) below summarizes the results of forecasting GDP and CPI over the period 2020 to 2022.

Table 2. The GDP and CPI forecasts

\begin{tabular}{cccccccc}
\hline Yare & $\begin{array}{c}\text { Actual } \\
\text { GDP }\end{array}$ & $\begin{array}{c}\text { Actual } \\
\text { CPI }\end{array}$ & $\begin{array}{c}\text { Forecast } \\
\text { GDP }\end{array}$ & $\begin{array}{c}\text { Forecast } \\
\text { CPI }\end{array}$ & $\begin{array}{c}\text { Forecast } \\
\text { RGDP }\end{array}$ & $\begin{array}{c}\text { Economic } \\
\text { Growth }\end{array}$ & inflation \\
\hline 2019 & 31597 & 125 & & & & & \\
\hline 2020 & --- & --- & 29342.12 & 128.31 & $\mathbf{2 2 8 6 8 . 1 5}$ & $\mathbf{- 0 . 0 9 5}$ & $\mathbf{0 . 0 2 9}$ \\
\hline 2021 & --- & --- & 32095.10 & 133.28 & $\mathbf{2 4 0 8 0 . 9 6}$ & $\mathbf{0 . 0 5 3}$ & $\mathbf{0 . 0 3 9}$ \\
\hline 2022 & --- & --- & $\mathbf{3 5 1 0 6 . 3 7}$ & $\mathbf{1 3 9 . 2 8}$ & $\mathbf{2 5 2 0 5 . 6 1}$ & $\mathbf{0 . 0 4 6}$ & $\mathbf{0 . 0 4 5}$ \\
\hline
\end{tabular}

It can be seen from Table 2 that the expected nominal GDP in 2020 amounts to 29342.12 million JD, which means that there is a decline by 2255 million JD compared to year 2019. When the growth rate of GDP had been calculated in 2020 (2010 base year), it was found that the Jordanian economy is expected to decline by $9.5 \%$, especially in light of the expectation of an increase of CPI to reach 128.3 in that year. Possibly, the main cause for this might be due to the Corona virus Pandemic 2019 (COVID-19) that has swept the world since the beginning of 2020, and it has led to the suspension of many economic activities around the world, particularly the Jordan economy which is small in size. Moreover, because of its openness and dependence to foreign economies, it has been greatly affected by (COVID-19).

Referring to table (2), we note that the GDP in 2021 is expected to start to recover to reach 32095 JD with a growth rate of about $3.9 \%$ compared to 2020 , and it will continue to rise in 2022 to reach $3506.36 \mathrm{JD}$, with a growth rate of 4.6\%. Consequently, it can be said that the Jordanian economy needs two years to recover from the shock that is expected to take place in the year 2020 and return to its original situation in light of the expectations of inflation rates that might reach $3.9 \%$ and $4.5 \%$ during the years 2021 and 2022 respectively.

\section{Conclusion}

The methodology of Box - Jenkins technique, which is a relatively advanced time series forecast method, is applied in this paper with the aim of forecasting GDP and CPI in Jordan for the three years (2020, 2021, and 2022). After testing the stationarity of the data using ADF and PP test, the series were stationary at the first difference after calculating the logarithm of the data. From the Correlogram of ACF, we determined the appropriate number of 
autoregressive terms $(\mathrm{P})$. From the Correlogram of PACF, we determined the appropriate number of moving average terms (q). Based on the minimum AIC and SIC, we chose the optimal ARIMA model which is ARIMA $(3,1,1)$ to forecast GDP for the years 2020, 2021, and 2022 as 29342.12, 32095,10, and 35106.37 respectively. We also chose ARIMA $(1,1,0)$ to forecast CPI for the years 2020, 2021, and 2022 as 128.28, 133.28, and 139.28 respectively.

According to the previous results, it can be concluded that the Jordanian economy is expected to experience a stagflation due to an expected decline in the size of GDP and an increase in CPI in the first stage. After that the output starts increasing until it reaches 35106.37 JD in 2022, accompanied by an increase in CPI. Furthermore, this would possibly happen as a result of a higher production costs especially due to the closures of the Corona pandemic. Therefore, the results of the current study will encourage economic policy-makers to formulate effective policies that help the Jordanian economy increase GDP and encounter the threat of inflation in order to emerge from the state of stagflation and make CPI more stable.

Finally, it should be noted that this study could not take into consideration the impact of COVID-19 pandemic on forecasting the values of GDP and CPI, despite its importance and the negative impact it had on the whole world. The reason behind this is that the annual figures of Jordanian GDP and CPI have not yet been announced. Therefore it is useful in the future to conduct studies to forecast some economic variables using the methodology of ARIMAX, which allows the addition of an external variable as an explanatory variable, and it may be appropriate that variable is a dummy variable to show the impact of the Corona pandemic on the values of the economic variables to be forecasted in the future

\section{References}

Abonazel, M. R., \& Abd-Elftah, A. I. (2019). Forecasting Egyptian GDP Using ARIMA Models. Reports on Economics and Finance, 5(1), 35-47.

Agrawal, V. (2018). GDP Modeling and forecasting using ARIMA: an empirical study from India. Doctoral dissertation, Central European University.

Anderson, O. (1976). Time Series Analysis and Forecasting. London: Butterworths.

Box, G. E., Jenkins, G. M., Reinsel, G. C., \& Ljung, G. M. (2015). Time series analysis: forecasting and control. John Wiley \& Sons.

Box, G. E. P., \& Jenkins, G. M. (1976). Time Series Analysis: forecasting and Control. San Francisco: Holden-Day, Cambridge.

Cecchetti, S. G. (1995). Inflation indicators and inflation policy. NBER macroeconomics annual, 10, 189-219.

Dongdong, W. (2010, August). The consumer price index forecast based on ARIMA model. In 2010 WASE International Conference on Information Engineering (Vol. 1, pp. 307-310). IEEE.

Dritsaki, C. (2015). Forecasting real GDP rate through econometric models: an empirical study from Greece. Journal of International Business and Economics, 3(1), 13-19.

Garnitz, J., Lehmann, R., \& Wohlrabe, K. (2019). Forecasting GDP all over the world using leading indicators based on comprehensive survey data. Applied Economics, 51(54), 5802-5816.

Gujarati, D. N., \& Porter, D. C. (2009). Basic econometrics. McGraw-Hill Education.

Kenny, G., Meyler, A., \& Quinn, T. (1998). Forecasting Irish inflation using ARIMA models (No. 3/RT/98). Central Bank of Ireland.

Kharimah, F., Usman, M., Widiarti, W., \& Elfaki, F. A. M. (2015). Time series modeling and forecasting of the consumer price index Bandar Lampung. Science International Lahore, 27(5), 4619-4624.

Kiriakidis, M., \& Kargas, A. (2013). Greek GDP forecast estimates. Applied Economics Letters, 20(8), 767-772.

Mills, T. (1990). Time Series Techniques for Economists. Cambridge University Press.

Nyoni, T. (2019). ARIMA modeling and forecasting of Consumer Price Index (CPI) in Germany (No. 92442). University Library of Munich, Germany.

Parkin, M. (2011). Microeconomics (10th ed.). Pearson Series in Economics, Prentice Hall.

Wabomba, M. S., Mutwiri, M. P., \& Mungai, F. (2016). Modeling and forecasting Kenyan GDP using autoregressive integrated moving average (arima) models. Science Journal of Applied Mathematics and Statistics, 4(2), 64-73.

Yang, B., Li, C., Li, M., Pan, K., \& Wang, D. (2016, December). Application of ARIMA model in the prediction of 
the gross domestic product. In 2016 6th International Conference on Mechatronics, Computer and Education Informationization (MCEI 2016). Atlantis Press.

\section{Note}

Note 1. One of the ARIMA features can add the error variance (SISQ) to the model as one of the explanatory variables, which was made in this study.

\section{Copyrights}

Copyright for this article is retained by the author(s), with first publication rights granted to the journal.

This is an open-access article distributed under the terms and conditions of the Creative Commons Attribution license (http://creativecommons.org/licenses/by/4.0/). 